\title{
Crowdinforming During Public Health Emergencies: A Commentary
}

\author{
Rebecca Roberts, $\mathrm{MD}^{1}$, Edward Mensah, $\mathbf{P h D}^{2}$ \\ ${ }^{1}$ John Stroger Hospital of Cook County, Chicago \\ ${ }^{2}$ University of Illinois at Chicago, School of Public Health
}

During the recent 2009 Novel H1N1 influenza pandemic, public health safety efforts included prevention and mitigation actions such as mass vaccination programs, community education focused on infection control, social distancing and how to avoid contracting and spreading influenza.[1-3] There were also programs to rapidly deploy caches of ventilators, antivirals and personal protective equipment to treat and reduce transmission of influenza infection.[1,3,4] Despite these efforts, many became ill.[12] Where and when to seek medical care was part of the public health education message.

The problem becomes continuing to meet concurrent public health prevention goals, plus ongoing medical obligations with existing staff and space.[4,6,7] The same medical staff members delivering antiviral medications to those exposed and running mass vaccination programs were also treating the ill. In addition, aggressive viral culture acquisition and special processing was instituted.[1,9] Screening for febrile employees and exposed personnel in high risk facilities was started so that antiviral prophylaxis could be rapidly administered. Alternate care sites were initiated to address the increased volumes and to sequester possibly infective patients. [1] Hospitals often make plans to delay routine care and redeploy the staff and treatment space if the influenza surge required this step.[6,7] In addition to all that new activity, some jurisdictions instituted new influenza-like-illness (ILI) reporting requirements for hospitals.[2] Even normal staffing levels may be insufficient to meet these new responsibilities and existing staff numbers may be further reduced due to illness during this pandemic.[10]

Emergency departments (EDs) are a good place to begin addressing load distribution during patient surge events such as the 2009 novel H1N1 pandemic. They are open 24/7, serve all who present for treatment, and do not incur the scheduling delays associated with primary care or other office-based appointments. They are prepared to address the most severe acuity of illness and are in hospitals which are often centrally located and highly familiar to the local community. Indeed, unprecedented patient surges were reported during the 2009 influenza season. [1, 8]

In OJPHI, Vol 2, No. 1, Bob McLeod introduced a novel combination of agent based modeling (ABM), electronic medical record dashboards to predict ED waiting room times, and Crowdinforming as a method to redistribute patients seeking ED care.[11] The purpose is to balance area hospital waiting room loads during pandemics surges. This is a very innovative idea with important applications in medicine and public health.

In short, they propose using EMR dashboards to estimate real-time ED patient waiting times for area hospitals.[11,12,13,14] This information is widely broadcast using the internet. The aim is 
to let potential ED patients add waiting room time to their decision-making on when and which ED to visit for current symptoms. This would help both patients seeking care and hospitals that often become overburdened during influenza season. We postulate that the model and the dissemination of the data have further important purposes.

The primary goal for any new medical innovation is better health in the community. With this in mind, we propose additional considerations to better inform decision making. We also recommend that the $\mathrm{ABM}$ and waiting room data are first communicated to key users such as the EDs, hospitals, clinics and local public health departments; enabling them to better collaborate in serving the community and to organize their staff and facilities to best address anticipated surge changes.

The ABM model and Crowdinforming might be inferred to refer only to ILI patients seeking emergency care and the waiting times might be construed as first-come, first-serve. Even during a pandemic, the majority of ED patients are there for other emergencies. Hospitals in Santiago, Chile, reported that 78\% of all ED visits were for influenza.[8] However, during the epidemic peak in Chicago, slightly more than 14\% of all ED visitors had ILI.[2] Among all U.S. ambulatory visits, approximately $16 \%$ were ILI and Australia's flutracking netted approximately 9\% ILI visits during the peak.[5,15]

Another key feature of ED waiting time is the triage procedure. Universally, systems are used to ensure that patients of high acuity are treated more rapidly than those with chronic, self-limited illness, or conditions where treatment success is not time-dependent. [16] In short, based on complex triage rules, severity of illness defines who waits the longest.[17] In the Crowdinforming model, this same concept would ideally apply to those who are deciding to seek care or considering long-distance travel to go to an ED with shorter waiting times. The problem becomes the degree of medical knowledge required to make these decisions wisely. A patient with a potential myocardial infarction (heart attack) or limb-threatening injury would wisely take an ambulance to the closest emergency department and expect to be seen immediately - even in an ED with long average waiting times. A patient with very mild ILI symptoms could safely wait several hours to see a clinician. At the same time, one would not want the mildly ill but contagious, coughing influenza patient to ride public transportation for an hour then wait in an ED infecting others. More importantly, antivirals are most effective in disease treatment and transmission prevention when started very early in the course of illness - while patients may not seek care for days or wait until they become quite severe. $[4,8,17]$ These issues are difficult for medical professionals to solve and may be even more difficult for potential patients or those who must develop public health messages to inform the community.[3,10,18,19]

Another resource that may inform this new modality is the literature on ED waiting room patients who left without being seen (LWBS). The literature indicates that longer waiting times, younger age and less severe disease are associated with LWBS.[20-23] However, this obscures the fact that even though age and acuity are statistically associated with waiting room behavior, some who leave do have high acuity problems.[17,21] The statistical tests gain strength from very large sample sizes. An important proportion of LWBS patients are hospitalized within a week.[21] The unintended consequence of Crowdinforming might be to influence a critically ill 
person to defer care or travel inordinate distances when they would best be seen at the closest hospital and triaged for immediate care.

Current staffing and medical supplies in departments critical to patient care must be taken into consideration when releasing information to the public that will cause rapid increases at the slower hospitals. Staff configuration at individual EDs and associated hospital wards, intensive care units, laboratories, pharmacies and radiology departments may need to be adjusted before Crowdinforming induces dramatic change.[7,12] EDs that are currently slow and might expect to remain slow could become swamped in the short-term. At the same time, overloaded hospitals may have instituted back-up staff and supply procedures for currently anticipated surge volumes, only to have the problems evaporate. For these reasons, we recommend that local public health departments, EMS, hospitals, and public education professionals should be closely involved in the formulation and response to Crowdinforming before messages are delivered to the public. This could foster cooperation and collaboration in the deployment of space, staff and supply resources throughout an area to best serve the public health.[3,6,7]

\section{$\underline{\text { References }}$}

1. Fagbuyi DB, Brown KM, Mathison DJ, Kingsnorth J, Morrison S, Saidinejad M, Greenberg J, Knapp M, Chamberlain JM. A Rapid Medical Screening Process Improves Emergency Department Patient Flow During Surge Associated With Novel H1N1 Influenza Virus. Ann Emerg Med. 2011; 57:52-9.

2. City of Chicago Department of Public Health. Pandemic Influenza A (H1N1) in Chicago, 2009. Communicable Disease Information. February 2010. Available at: http://www.cityofchicago.org/content/dam/city/depts/cdph/infectious_disease/Communicable Disease/IP_CDInfo_FEB2010_PandemicFlu.pdf. Assessed December, 2010.

3. Bishop JF, Murnane MP, Owen R. Australia's Winter with the 2009 Pandemic Influenza A (H1N1) Virus. NEJM. 2009; 361:2591-2594.

4. Bradt DA, Drummond CM. Avian influenza pandemic threat and health systems response. Emerg Med Australas. 2006; 18:430-43.

5. Centers for Disease Control and Prevention. 2010-2011 Influenza Season Week 50 ending December 18, 2010. Dec 23, 2010. Available at: http://www.cdc.gov/flu/weekly/ Accessed December, 2010.

6. U.S. Department of Homeland Security. Target Capabilities List - A companion to the National Preparedness Guidelines. September 2007. Available at: http://www.fema.gov/pdf/government/training/tcl.pdf. Accessed May 2010.

7. Hospital Incident Command System. External Scenario 3: Biological Disease Outbreak Pandemic influenza. Available at: http://www.emsa.ca.gov/HICS/files/Ext_03.pdf. Accessed April 2010.

8. Torres JP, O'Ryan M, Herve B, Espinoza R, Acuna G, Manalich J, Chomali M. Impact of the novel influenza A (H1N1) during the 2009 autumn-winter season in a large hospital setting in Santiago, Chile. Clin Infect Dis. 2010; 50:869-70. 
9. Cheng PK, Wong KK, Mak GC, Wong AH, Mg AY, Chow SY, Lam RK, Lau Cs, Ng KC, Lim W. Performance of laboratory diagnostics for the detection of influenza A (H1N1) virus as correlated with the time after symptom onset and viral load. J Clin Virol. 2010; 47:182-5.

10. Lipsitch M, Phil D, Riley S, Phil D, Cauchemez S, Ghani AC, Ferguson NM. Managing and Reducing Uncertainty in an Emerging Influenza Pandemic. NEJM. 2009; 361;2:112-15.

11. McLeod B. Agent based modeling of "Crowdinforming" as a Means of Load Balancing at Emergency Departments. Online Journal of Public Health Informatics. 2010 - Vol 2, No. 1.

12. Gunal MM, Pidd M. Understanding Accident and Emergency Department Performance Using Simulation. Proceedings of the 2006 Winter Simulation Conference. 2006, pages 44652.

13. Bonabeau E. Agent-based modeling: Modeling and techniques for simulating human systems. PNAS. 2002; 99:7280-87.

14. Laskowski M, McLeod RD, Friesen MR, Podaima BW, Alfa AS. Models of Emergency Departments for Reducing Patient Waiting Times. PLoS ONE. 2009; 4:e6127.

15. Carlson SJ, Dalton CB, Durrheim DN, Fesja J. Online Flutracking Survey of Influenza-like Illness during Pandemic (H1N1) 2009, Australia. Emerg Inf Dis. 2010; 16,12:1960-1962.

16. Bernstein SL, Argonsky D, Duseja R, Epstein S, Handel D, Hwang U, McCarthy M, McConnell KJ, Pines JM, Rathlev N, Schafermeyer R, Zwemer F, Schull M, Asplin BR. The Effect of Emergency Department Crowding on Clinically Oriented Outcomes. Acad Emerg Med. 2009; 16:1-10.

17. Zarychanski R, Stuart TL, Kumar A, Doucette S, Elliot L, Kettner J, Plummer F. Correlates of severe disease in patients with 2009 pandemic influenza (H1N1) virus infection. CMAJ. 2010; 182:257-64.

18. Osterholm MT. Preparing for the Next Pandemic. NEJM. 2005; 352:1839-42.

19. Kendal AP, MacDonald NE. Influenza pandemic planning and performance in Canada, 2009. Can J Public Health. 2010; 101:447-53.

20. Kennedy M, MacBean CE, Brand C, Sundararajan V, McD Taylor D. Review article: Leaving the emergency department without being seen. Emerg Med Australas. 2008; 20:30613.

21. Baker DW, Stevens CD, Brook RH. Patients Who Leave a Public hospital Emergency Department Without Being Seen by a Physician. JAMA. 1991; 266:1085-90.

22. Kulstad EB, Hart KM, Waghchoure S. Occupancy Rates and Emergency Department Work Index Scores Correlate with Leaving Without Being Seen. WestJEM. 2010; 11:324-28.

23. Baibergenova A, Leeb K, Jokovic A, Gushue S. Missed Opportunity: Patients Who Leave Emergency Departments without Being Seen. Healthcare Policy. 2006 1;35-41. 